\section{Gender, Math Confidence, and Grit: Relationships with Quantitative Skills and Performance in an Undergraduate Biology Course}

\author{
K. M. Flanagan ${ }^{\dagger *}$ and J. Einarson* \\ ${ }^{\dagger}$ Department of Biological Sciences, University of Calgary, Calgary, AB T2N 1N4, Canada; ;Calgary \\ Board of Education, Calgary, AB T2R OL4, Canada
}

\begin{abstract}
In a world filled with big data, mathematical models, and statistics, the development of strong quantitative skills is becoming increasingly critical for modern biologists. Teachers in this field must understand how students acquire quantitative skills and explore barriers experienced by students when developing these skills. In this study, we examine the interrelationships among gender, grit, and math confidence for student performance on a pre-post quantitative skills assessment and overall performance in an undergraduate biology course. Here, we show that females significantly underperformed relative to males on a quantitative skills assessment at the start of term. However, females showed significantly higher gains over the semester, such that the gender gap in performance was nearly eliminated by the end of the semester. Math confidence plays an important role in the performance on both the pre and post quantitative skills assessments and overall performance in the course. The effect of grit on student performance, however, is mediated by a student's math confidence; as math confidence increases, the positive effect of grit decreases. Consequently, the positive impact of a student's grittiness is observed most strongly for those students with low math confidence. We also found grit to be positively associated with the midterm score and the final grade in the course. Given the relationships established in this study among gender, grit, and math confidence, we provide "instructor actions" from the literature that can be applied in the classroom to promote the development of quantitative skills in light of our findings.
\end{abstract}

\section{INTRODUCTION}

One of the most difficult challenges we face as teachers is understanding why some students succeed in a course while others struggle. Success seems to be the result of an unknowably complex myriad of factors, including: prerequisite background knowledge, hidden misconceptions, sense of confidence, motivation, relevance of the subject matter, and a student's sheer will and determination. Given all these factors, it is also hard to know in what ways we as teachers influence student success. What factors are impeding or promoting student learning in our courses? How do students' innate characteristics and personalities influence their performance? How can we as teachers alleviate impediments and enhance factors promoting student learning? Here we explore how students' acquisition of quantitative skills and success in an undergraduate biology course are influenced by the interrelationships among confidence in their mathematical abilities, their determination for achieving long-term goals_or grit, and gender.

Quantitative skills are increasingly important in biological sciences (Bialek and Botstein, 2004; Cohen, 2004; Ramaley, 2004; Speth et al., 2010; Colon-Berlingeri and Burrowes, 2011; Feser et al., 2013). Despite the importance of such skills, it has been found that many biology students struggle with quantitative skills such as performing
Marshall Sundberg, Monitoring Editor Submitted August 19, 2016; Revised May 11, 2017; Accepted May 24, 2017

CBE Life Sci Educ September 1, 2017 16:ar47 DOI:10.1187/cbe.16-08-0253

*Address correspondence to: K. M. Flanagan (kmflanag@ucalgary.ca).

(C) 2017 K. M. Flanagan and J. Einarson. CBE-Life Sciences Education @ $\odot 2017$ The American Society for Cell Biology. This article is distributed by The American Society for Cell Biology under license from the author(s). It is available to the public under an Attribution-Noncommercial-Share Alike 3.0 Unported Creative Commons License (http://creativecommons.org/licenses/ by-nc-sa/3.0).

"ASCB ${ }^{\oplus "}$ and "The American Society for Cell Biology ${ }^{\circledR n}$ are registered trademarks of The American Society for Cell Biology. 
simple calculations, creating and interpreting graphical representations of data or functional relationships, and creating arguments based on numerical data (Speth et al., 2010; Feser et al., 2013). There is a concern that, even though biology students are required to take many math courses leading up to and as part of their biology degrees, they are still not prepared to a deep enough level of quantitative thinking. Students often seem unable to synthesize their own analyses or develop novel mathematical representations of biological processes, as required in the new professional world of biology (Bialek and Botstein, 2004). To be successful as biologists, students need to understand mathematical concepts, but they must also be able to fluently connect these concepts to variables in the natural world and relate mathematical measures to measurements that are taken in the lab or in the field (Aikens and Dolan, 2014).

We explored quantitative skills not only because they are critically important for modern biologists, but also because quantitative skills and mathematics in general tend to be wrapped up in all varieties of preconceptions, biases, and gender stereotypes and can be a sticking point for those who otherwise are confident learners (Betz, 1978; Cvencek et al., 2011; Rubinsten et al., 2012). Many undergraduates, and even highly educated academics, who tend to have a growth mind-set in most realms (Dweck, 2006), can assume a very fixed mind-set in this particular area, making statements like "I am just not a math person" (Dweck, 2008; Rattan et al., 2012). Self-identification as a "math person" (or not) likely stems from varying degrees of confidence in mathematical abilities, confidence in ability to learn math, and experiences with math anxiety (Ashcraft, 2002; Ahmed et al., 2012; Jansen et al., 2013). Predictors and factors influencing math confidence and anxiety have been widely studied. Important factors include early childhood experiences with math (Krinzinger et al., 2009; Lefevre et al., 2009), characteristics of early childhood math teachers (Beilock et al., 2010; Chen et al., 2013), gender stereotypes with regard to math abilities (Miller and Bichsel, 2004; Murphy and Thomas, 2008; Cvencek et al., 2011; Passolunghi et al., 2014), parents' attitudes toward math (Gunderson et al., 2012; Casad et al., 2015), and stereotype threat in females (Spencer et al., 1999; Kiefer and Sekaquaptewa, 2007). In the past, gender was consistently identified as an important factor associated with math confidence, math anxiety, and performance on math assessments; however, there is evidence that the underperformance of females relative to males in math is disappearing, at least in $\mathrm{K}-12$ (Hyde et al., 2008). Furthermore, the gender gap in math is correlated to cultural differences in gender equality; as the gender status of women improves, the gender gap in math is eliminated (Guiso et al., 2008). In a female-dominated discipline such as biology (Cheryan, 2012; Su and Rounds, 2015), it is often assumed that gender disparities do not exist at the undergraduate level (Eddy et al., 2014). Females typically account for more than $60 \%$ of undergraduate biology majors (Luckenbill-Edds, 2002; Wright et al., 2016). Given the overrepresentation of females in undergraduate biology, many instructors may assume that a numerical majority means equality in other aspects in the classroom. However, even when females are the majority, disparities can persist. For example, in large undergraduate biology courses, females underperform on exams compared with males of similar overall grade point average and participate less during class time (Eddy et al., 2014;
Wright et al., 2016). Failing to consider and explore gender disparities hidden behind numerical dominance in biology at the undergraduate level may perpetuate persistent gender gaps at the postgraduate level or in academic positions. This could be particularly important for quantitative skills required in biology, where strong historical patterns may remain despite numerical dominance.

We know that students' past experiences and factors such as gender can have an overarching impact on student performance in quantitative fields. However, it is less clear how the personality dispositions of individual students influences their academic success in this context. Grit is one measure of an individual's disposition we anticipate could have an influence on student success in a course. Grit is a characteristic defined by Angela Duckworth as a person's perseverance and passion for long-term goals (Duckworth et al., 2007). It is in the family of conscientiousness traits, which can be broken into two components: 1) perseverance of effort and 2) consistency of interest over time (Bowman et al., 2015). Grit has been examined in many contexts and is correlated to aspects of success in many different realms, from spelling bees to the military (Duckworth et al., 2011; Goodwin and Miller, 2013; Perkins-Gough, 2013; Rimfeld et al., 2016). In postsecondary education, grit has been correlated with self-reported grades (Duckworth and Quinn, 2009; Wolters and Hussain, 2015); however, there is limited direct evidence of a link between grit and academic achievement, leading us to explore whether grittier students are able to outperform less gritty students in a gender-biased and anxiety-charged subject such as math in a postsecondary setting. Understanding the role traits such as grit play in academic success at the postsecondary level is important, because these characteristics may be malleable and therefore could be targeted for intervention.

We know that quantitative reasoning skills are essential for undergraduate biology majors and that there is potential for differences between males and females in these skills, but little is known about the role of learner characteristics, like grit, in this context. To explore this, we examined the relationships between quantitative skills measured when the student enters an undergraduate biology course, gains in quantitative skills over the semester, overall course performance, the students' math confidence, and grit for males and females. Given this context, the objectives of this study are as follows:

- Objective 1: Determine whether males and females differ in their performance on a quantitative skills pre- and postassessment, and whether males and females rate themselves differently in math confidence and grit.

- Objective 2: Determine whether performance on an assessment of students' quantitative skills at the start of a semester and the change in quantitative skills during a semester are predicted by math confidence, grit, and gender.

- Objective 3: Determine whether there are patterns of association between pre- and postassessment quantitative skills, math confidence, grit, performance on exams, and overall performance in a course.

\section{MATERIALS AND METHODS Context and Participants}

We conducted this study over the 13-week Winter semester (January to April) of 2014 in a second-year introductory ecology 
course at a research-intensive university in Canada. This course is a required for all students in our biological sciences, plant science, zoology, and ecology majors programs. Course topics include: evolution, behavioral ecology, life history theory, sexual selection, density-independent and density-dependent growth, age-structured population growth, spatial population ecology, physiological ecology, community ecology, Lotka-Volterra predator-prey relationships, Lotka-Volterra competition theory, species abundance and diversity, parasitism, nutrients and energy flow, and landscape and global ecology. Face-to-face instruction occurs during three 50-minute lectures per week and in a 3-hour mandatory weekly laboratory.

The total enrollment for the course was 181 students. Students varied in their year of program, with $74 \%$ in their second year, $13 \%$ in their third year, and $\sim 4 \%$ in their fourth year or higher. The gender ratio of the class was approximately $67 \%$ females and 32\% males. Of the 181 students, 169 (93\%) consented to be a part of the study. The demographics of the consenting students were similar to those of the class as a whole. K.M.F. was the instructor for the course.

Some of the quantitative skills we expect for successful completion of this course include: reading and interpreting graphs on arithmetic and logarithmic scales; basic statistical analyses, including $t$ tests and chi-square tests; using mathematical formulas to represent biological processes; examining state space graphs to determine stability of equilibria; and writing and solving coupled ordinary differential equations describing biological processes. There are no math or calculus prerequisites for the course; however, students are required to take two math courses (calculus I and calculus II or linear algebra I) for degree completion. The majority of students complete these math requirements in their first year of the program.

\section{Study Design and Tools}

To explore our objectives regarding the acquisition of quantitative skills in undergraduate biology students, we conducted preand posttesting for crucial quantitative skills and calculated gains in these quantitative skills over the semester. The preassessment also included an assessment of students' math confidence and grit. The pre- and posttest scores, gains, and course performance were correlated with measures of math confidence and grit. We explored the performance measures with confidence and grit measures for self-identified males and females to examine relationships with gender.

Pretest Format. The pretest targeted key quantitative skills required for this course (Table 1 ). The questions were selected from quantitative skills assessment tools used in Thompson et al. (2010) and Chevalier et al. (2010). We assessed students' math confidence by the widely used Fennema-Sherman Mathematics Attitude Scale-Confidence Subscale (Fennema and Sherman, 1976). We used three of the 15 subscale items and selected those with high factor structure coefficients from a principal component analysis (Mulhern and Rae, 1998). We measured the alpha Cronbach value for the Fennema-Sherman Confidence subscale used in this study. The alpha value was

TABLE 1. Composition of the pretest in terms of quantitative skills, math confidence, and grit

\begin{tabular}{|c|c|c|}
\hline \multicolumn{3}{|r|}{ Quantitative skills assessment } \\
\hline Item source & Item numbers & Targeted skill \\
\hline Chevalier et al., 2010 & $1,8,13$ & Interpretation of graphically presented biological data, data characteristics \\
\hline & $17,28,30$ & Statistical inference, ability to analyze data statistically \\
\hline Thompson et al., 2010 & $1,2,6,8,9,11,17$ & Using mathematical models to represent biological systems \\
\hline & 3 & Presenting biological data graphically \\
\hline & 4 & Ability to analyze data statistically \\
\hline & 7,20 & Applying probabilities to problems \\
\hline & 12,13 & Interpreting figures on a logarithmic scale \\
\hline & 14,19 & Interpreting figures on an arithmetic scale \\
\hline \multicolumn{3}{|r|}{ Math confidence } \\
\hline Item source & Item numbers & Five-level Likert-scale statements (strongly agree to strongly disagree) \\
\hline $\begin{array}{l}\text { Fennema-Sherman Mathematics } \\
\text { Attitude Scale-Confidence } \\
\text { subscale (Fennema and } \\
\text { Sherman, 1976) } \\
\end{array}$ & $\begin{array}{l}\text { Confidence } \\
\text { subscale: } 5,7 \text {, } \\
\text { and } 10\end{array}$ & $\begin{array}{l}\text { 1. I'm no good at math. } \\
\text { 2. For some reason, even though I study, math seems unusually hard for me. } \\
\text { 3. I can get good grades in math. }\end{array}$ \\
\hline \multicolumn{3}{|r|}{ Grit } \\
\hline Item source & Item numbers & Five-level Likert-scale questions (very much like me to not like me at all) \\
\hline Duckworth and Quinn, 2009 & $\begin{array}{c}\text { All eight items on } \\
\text { the grit scale }\end{array}$ & $\begin{array}{l}\text { 1. New ideas and projects sometimes distract me from previous ones. } \\
\text { 2. Setbacks don't discourage me. } \\
\text { 3. I have been obsessed with a certain idea of project for a short time but later lost } \\
\text { interest. } \\
\text { 4. I am a hard worker. } \\
\text { 5. I often set a goal but much later choose to pursue a different one. } \\
\text { 6. I have difficulty maintaining my focus on projects that take more than a few months } \\
\text { to complete. } \\
\text { 7. I finish whatever I begin. } \\
\text { 8. I am diligent. }\end{array}$ \\
\hline
\end{tabular}


0.78 , suggesting there is a good level of internal consistency for this measure, even with the reduced subscale. The entire eightpoint Grit Short Scale was used (Duckworth and Quinn, 2009). Table 1 shows the breakdown of items used on the pretest (see the Supplemental Material for the entire pretest).

During the Semester. We provided students with online resources (Supplemental Material) to assist them in the development of quantitative skills. Students were able to see their performance on the pretest and were given the opportunity to review the pretest with K.M.F. to identify their quantitative strengths and weaknesses. Approximately $10 \%$ of the class took the opportunity to go over the preassessment with the instructor. Many of the quantitative skills were not explicitly taught in lecture or lab (i.e., we did not have a series of lectures on quantitative skills). Rather, the quantitative skills were integrated and infused into the content of lectures and labs through their application to biological problems. For example, students were statistically analyzing data they had collected in labs, or we were using mathematical models to explore biological concepts during class. However, the emphasis was on the use of quantitative skills as a tool to understand biology, not as an explicit content topic.

Posttest Format. Students completed the postassessment during the last week of labs (Supplemental Material). The posttest contained questions matched to those asked on the pretest.

\section{Statistical Analysis}

All analyses were performed using the statistical package $R$, version 3.3.1. Scores for math confidence and grit were calculated by averaging all Likert-scale question responses on a scale from 1 to 5 to produce a single math confidence and grit score for each student (Duckworth and Quinn, 2009). Larger confidence and grit scores indicate greater confidence and more grit. Change in quantitative skills as measured from the pre- and posttesting were estimated as normalized change (c) calculated for each student (Marx and Cummings, 2007):

$c=\left\{\begin{array}{c}\text { if post }>\text { pre, then }\left(\frac{\text { post }- \text { pre }}{1-\text { pre }}\right) \\ \text { if post }=\text { pre, then } c=0 \\ \text { if pre }>\text { post, then }\left(\frac{\text { post }- \text { pre }}{\text { pre }}\right)\end{array}\right.$

Normalized change is a common way of measuring change in pre- and posttest scores. It ranges from -1 to +1 , with zero representing no change in pre- and posttest scores, negative scores representing a decrease in performance, and positive scores representing an improvement in performance on the posttest (Marx and Cummings, 2007).

To evaluate objective 1 , we conducted nonparametric two-sample Fisher-Pitman Permutation tests (due to nonnormality) to determine whether there were significant differences between pre- and posttest scores, normalized change scores, math confidence, and grit between males and females. The permutation analyses were implemented in $\mathrm{R}$ using the "coin" package. To assess objective 2 , we conducted a linear model with pretest score as the dependent variable and grit, math confidence, gender, and interactions as predictor variables. The same analysis was conducted with normalized change and posttest score to determine whether math confidence, grit, and gender were predictors of the change in quantitative skills over the semester. These analyses were conducted using $\operatorname{lm}()$ and aov() in the "base" package in R. The full models tested were:

1. Pretest score $=$ grit + math confidence + gender + grit * math confidence + grit * gender + gender * math confidence + grit * math confidence * gender

2. Normalized change $=$ grit + math confidence + gender + grit * math confidence + grit * gender + gender *math confidence + grit * math confidence * gender

3. Posttest score $=$ grit + math confidence + gender + grit * math confidence + grit * gender + gender * math confidence + grit * math confidence*gender

To assess objective 3, we conducted a nonparametric Spearman's correlation analysis between math confidence, grit, preand posttest scores, normalized change, performance in the course, and performance on high-stakes assessments (midterm and final exam).

\section{RESULTS}

\section{Objective 1}

The average percentage score on the quantitative skills pretest was $62.8 \%$, with a range in scores of $28.57 \%$ to $95.24 \%$. There was a significant difference in the mean pretest scores of males $\left(\bar{Y}_{\text {pretest males }}=70.63 \%, S D=10.57 \%\right)$ and females $\left(\bar{Y}_{\text {pretest females }}=59.73 \%, \mathrm{SD}=10.25 \% ; p<<<0.001 ;\right.$ Figure 1$)$. We also found a significant difference in the mean posttest

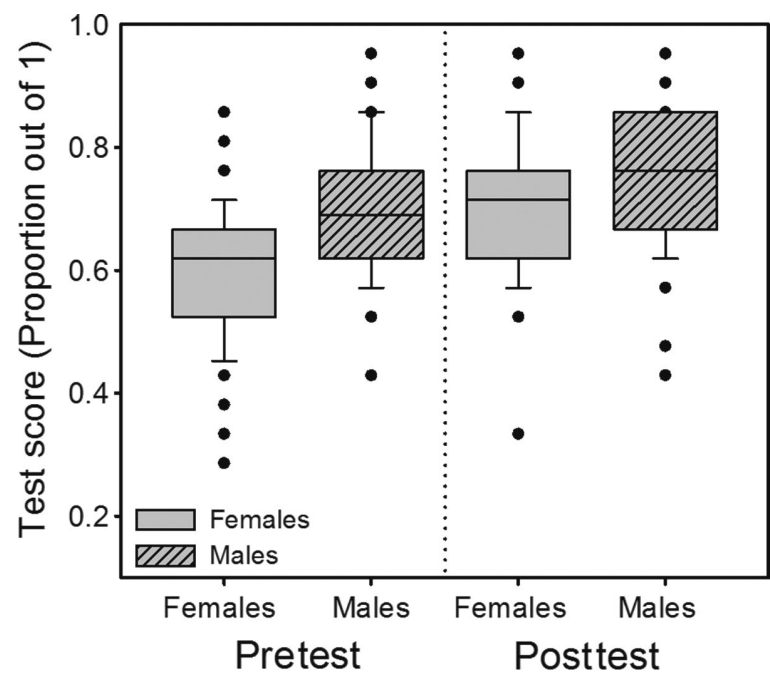

FIGURE 1. Box plot of the test scores (as a proportion out of 1) for self-identified females (gray fill) and males (lined fill) on the quantitative skills pretest and posttest in a second-year undergraduate biology course. The boundary of the box closest to zero indicates the 25 th percentile, the line within the box marks the median, and the boundary of the box farthest from zero indicates the 75th percentile. Whiskers (error bars) above and below the box indicate the 90 th and 10 th percentiles. Dots beyond the whiskers are values more extreme than the 90 th or 10th percentile. 


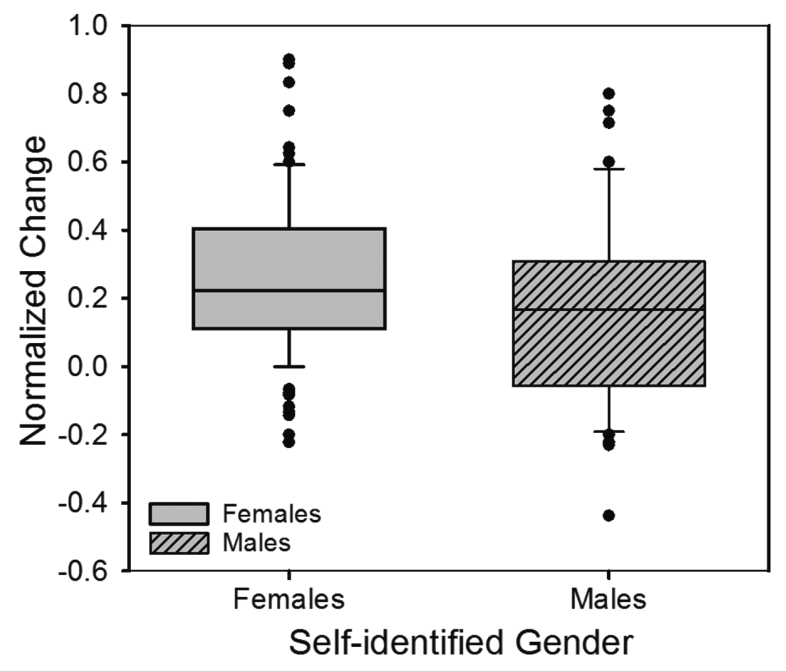

FIGURE 2. Box plot of normalized change based on the quantitative skills pre- and posttest for self-identified females (gray fill) and males (dashed fill) in a second-year undergraduate biology course. Normalized change values greater than zero indicate an increase in score on the posttest relative to the pretest, values less than zero indicate a decrease in performance on the posttest relative to the pretest. The boundary of the box closest to zero indicates the 25th percentile, the line within the box marks the median, and the boundary of the box farthest from zero indicates the 75th percentile. Whiskers (error bars) above and below the box indicate the 90th and 10th percentiles. Dots beyond the whiskers are values more extreme than the 90 th or 10th percentile.

scores between males and females $(p<0.05)$; however, the gap between the mean performance of males $\left(\bar{Y}_{\text {posttest males }}=74.63 \%\right.$, $\mathrm{SD}=11.09 \%)$ and females $\left(\bar{Y}_{\text {posttest females }}=70.30 \%, \mathrm{SD}=\right.$ $11.19 \%)$ on the posttest was less than the gap for the pretest. The normalized change scores based on a student's pre- and posttest scores were significantly greater than zero $(95 \%$ bootstrap confidence interval: $0.1936<0.216>0.2694$ ), indicating on average there was a significant gain in quantitative skills over the semester (Figure 2). We also found significant difference in the mean normalized change scores for males and females $(p<0.05)$, with females having higher positive change scores $\left(\bar{Y}_{\text {normalized change females }}=0.2575, \mathrm{SD}=0.2399\right)$ than males $\left(\bar{Y}_{\text {normalized change males }}=0.1693, \mathrm{SD}=0.2853\right)$. There was no significant difference in the mean grit scores of males $\left(\bar{Y}_{\text {grit males }}=3.389, \mathrm{SD}=0.5453\right)$ and females $\left(\bar{Y}_{\text {grit females }}=3.440\right.$, $\mathrm{SD}=0.4656 ; p>0.05$; Figure 3 ). Nor was there any difference inthemeanmathconfidenceformales $\left(\bar{Y}_{\text {math confidence males }}=3.753\right.$, $\mathrm{SD}=0.8251)$ and females $\left(\bar{Y}_{\text {math confidence males }}=3.733, \mathrm{SD}=\right.$ 0.8357; $p>0.05$; Figure 3).

\section{Objective 2}

When the factors predicting students' pretest scores were examined, math confidence $(p<0.001)$, gender $(p<0.001)$, and an interaction between math confidence and grit $(p<0.05)$ were significant predictors of the students' pretest scores (Table 2). The partial regression coefficient describing the relationship between math confidence and pretest score was positive and significantly different from zero $(\beta=0.1522 \pm 0.059$ [SE], $p<$ 0.001 ), indicating that, as math confidence increases, so too
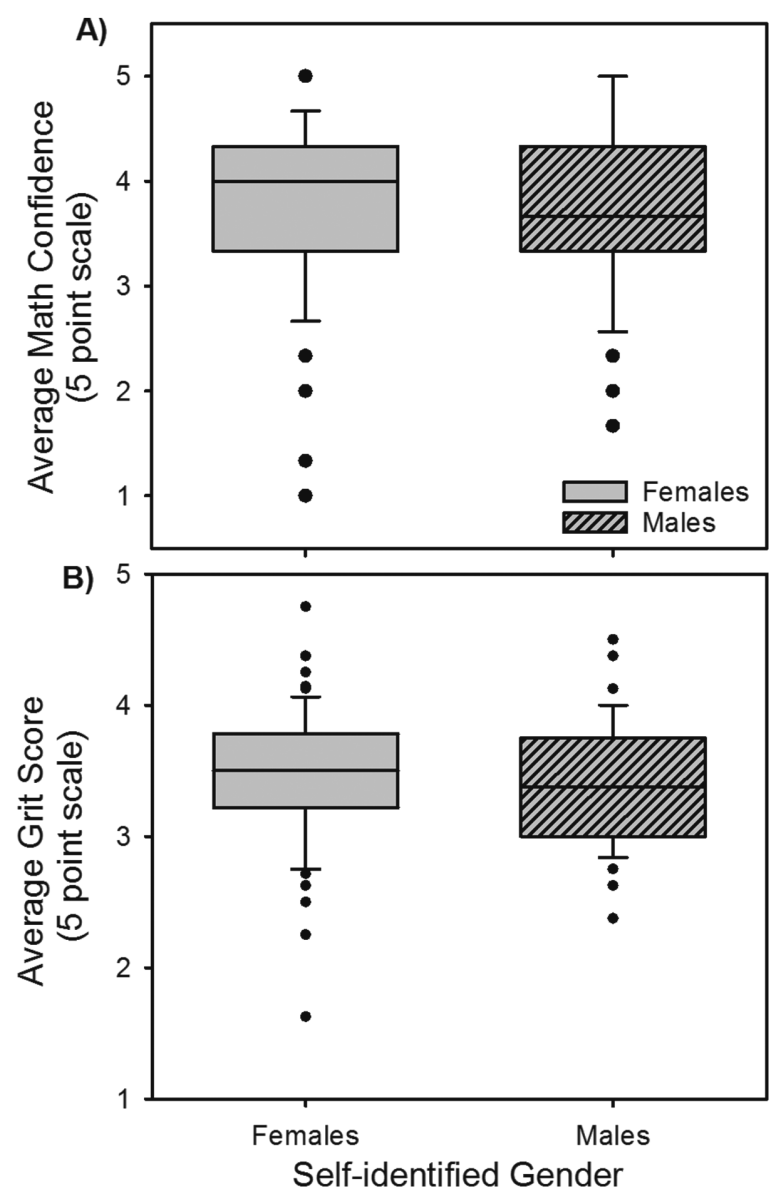

FIGURE 3. (A) Box plot of the average math confidence scores (on a scale from 1 to 5) for self-identified females (gray fill) and males (dashed fill) in a second-year undergraduate biology course. Math confidence scores of 5 indicate high levels of math confidence, whereas math confidence scores of 1 indicate low levels of math confidence. (B) Box plot of the average grit score (on a scale from 1 to 5) for males and females, with larger grit scores indicating an increase in grit. The boundary of the box closest to zero indicates the 25th percentile, the line within the box marks the median, and the boundary of the box farthest from zero indicates the 75th percentile. Whiskers (error bars) above and below the box indicate the 90th and 10th percentiles. Dots beyond the whiskers are values more extreme than the 90 th or 10th percentile.

does the student's performance on the pretest. The partial regression coefficient for the significant interaction between math confidence and grit was negative $(\beta=-0.0366 \pm 0.015629$, $p<0.05)$. This significant negative interaction between math confidence and grit indicates that, as one variable increases, the positive slope of the other decreases. As confidence increases, the effect of grit on pretest score is altered. Those students who have high math confidence and rate themselves highly in terms of grit underperform relative to those students who have high math confidence but rate themselves lower in terms of grit. For low-confidence students, the opposite is true; grittier students who have low math confidence perform better than less gritty students do. Thus, the significant negative interaction between confidence and grit indicates that the effect of grit is mediated by the students' confidence. An increased grit score has a 
TABLE 2. Partial regression coefficients $(\beta \pm S E)$, sum of squares (SS), degrees of freedom $(d f), F$ ratio $(F)$, and probabilities $(p)$ associated with each of the terms in the general linear model predicting pretest scores ${ }^{a}$

\begin{tabular}{|c|c|c|c|c|c|}
\hline Source & $\beta \pm S E$ & SS & $d f$ & $F$ & $p$ \\
\hline Grit & $0.1120 \pm 0.0584$ & 0.0066 & 1 & 0.6686 & 0.4148 \\
\hline Math confidence & $0.1523 \pm 0.0519$ & 0.1312 & 1 & 13.3420 & $0.0003566 * * *$ \\
\hline Gender & $0.0820 \pm 0.7792$ & 0.3524 & 1 & 35.8485 & $1.477 \mathrm{e}-08^{* * *}$ \\
\hline Grit * math confidence & $-0.0367 \pm 0.0156$ & 0.0557 & 1 & 5.6653 & $0.0185437^{*}$ \\
\hline Grit * gender & $-0.0056 \pm 0.2283$ & 0.0103 & 1 & 1.0509 & 0.3069 \\
\hline Math confidence * gender & $-0.0278 \pm 0.2047$ & 0.0026 & 1 & 0.2589 & 0.6116 \\
\hline Grit * math confidence * gender & $0.0114 \pm 0.0600$ & 0.0004 & 1 & 0.0358 & 0.8502 \\
\hline Residuals & & 1.4942 & 152 & & \\
\hline
\end{tabular}

${ }^{\mathrm{a}} R^{2}=0.2428$.

Significance codes: ${ }^{*} p<0.05 ;{ }^{* *} p<0.01 ;{ }^{* *} p \leq 0.001$. Bold, $p<0.1$.

positive effect for the students with low math confidence, but a negative effect for the students with high math confidence. The adjusted $R^{2}$ value for the model was 0.2428 . Inspection of the quantile-quantile plot for this analysis indicates that the residuals are normally distributed. The variance inflation factors for the predictor variables (grit, gender, math confidence) showed very little collinearity (VIF values $<2$ ), and there was no autocorrelation between the residuals.

The factors predicting normalized change scores were also examined using a linear multiple regression model with gender, grit, and math confidence. Only gender was a significant predictor of normalized change scores $(p<0.1)$, reflecting the higher average normalized change scores for females (Table 3). Inspection of the quantile-quantile plot of the residuals reveals a slight deviation from normality; however, with a sample size this large, minor deviations from normality should not influence the outcome of the analysis. There was no autocorrelation between the residuals.

In the model examining posttest scores, math confidence was a significant predictor of posttest score $(p<0.001)$ and gender ( $p<0.05$; Table 4$)$. There was also a significant interaction between grit and math confidence $(p<0.05)$ and weakly significant interaction between gender and grit $(p<0.1)$. The partial regression coefficient for math confidence was positive ( $\beta=0.16083 \pm 0.05571[\mathrm{SE}], p<0.01)$ indicating that, as math confidence increases, the performance on the posttest also increases. The partial regression coefficient for the interaction between grit and math confidence was negative ( $\beta=-0.03774$ \pm 0.01678 [SE],$p<0.05$ ), as was observed in the pretest, indicating that the effect of grit depends on the math confidence of the students. For the weakly significant interaction between gender and grit, the partial regression coefficient was positive $(0.23345 \pm 0.24516, p>0.05)$. This indicates that the positive effect of grit on posttest scores was greater for females that it was for males. The $R^{2}$ value for this model was 0.1134 . Inspection of the quantile-quantile plot for this analysis indicates that the residuals are normally distributed, and there was no autocorrelation between the residuals. For all three of these models, grit was also examined by dividing it into the two component parts: perseverance of effort and consistency of interest (Bowman et al., 2015) to explore whether either of these components of grit was a better predictor of performance on the quantitative skills assessments. However, both perseverance of effort and consistency of interest showed the same qualitative results as when grit was explored as a single dimension.

\section{Objective 3}

Spearman's nonparametric correlation matrix was produced to examine patterns between the variables in this study (Table 5). Grit was not significantly correlated with math confidence, pretest or posttest score, normalized change, or final exam score. However, grit was weakly associated with the midterm exam score $(p<0.10)$ and the final grade in the course $(p<$ $0.10)$. Math confidence showed significant positive correlations with pretest score $(p<0.01)$, posttest score $(p<0.01)$, the midterm exam score $(p<0.05)$, and a weak association with the final grade $(p<0.1)$. The pretest score was strongly positively correlated with the posttest score $(p<0.001)$ and with the midterm exam score $(p<0.01)$. The posttest was strongly positively correlated with the midterm exam score $(p<0.001)$ and with the final grade in the course $(p<0.05)$ and weakly associated with the final exam score $(p<0.1)$. Normalized

TABLE 3. Partial regression coefficients $(\beta \pm$ SE), sum of squares (SS), degrees of freedom $(d f), F$ ratio $(F)$ and probabilities $(p)$ associated with each of the terms in the general linear model predicting normalized change scores

\begin{tabular}{|c|c|c|c|c|c|}
\hline Source & $\beta \pm S E$ & SS & $d f$ & $F$ & $p$ \\
\hline Grit & $0.0253 \pm 0.1509$ & 0.0553 & 1 & 0.8439 & 0.3597 \\
\hline Math confidence & $0.0348 \pm 0.1340$ & 0.0345 & 1 & 0.5263 & 0.4693 \\
\hline Gender (reference: males) & $-1.5182 \pm 2.0121$ & 0.2474 & 1 & 3.7745 & 0.0539 \\
\hline Grit * math confidence & $-0.0034 \pm 0.0404$ & 0.0040 & 1 & 0.0604 & 0.8061 \\
\hline Grit * gender & $0.4415 \pm 0.5897$ & 0.0800 & 1 & 1.2206 & 0.2710 \\
\hline Math confidence * gender & $0.2874 \pm 0.5286$ & 0.0071 & 1 & 0.1080 & 0.7429 \\
\hline Grit * math confidence * gender & $-0.0901 \pm 0.1551$ & 0.0221 & 1 & 0.3374 & 0.5622 \\
\hline Residuals & & 9.9622 & 152 & & \\
\hline
\end{tabular}

Significance codes: Bold, $p<0.1 ; * p<0.05 ; * * p<0.01 ; * * * p \leq 0.001$. 
TABLE 4. Partial regression coefficients $(\beta \pm S E)$, sum of squares (SS), degrees of freedom $(d f), F$ ratio $(F)$, and probabilities $(p)$ associated with each of the terms in the linear model predicting posttest scores ${ }^{a}$

\begin{tabular}{lccccc}
\hline Source & $\boldsymbol{\beta} \pm$ SE & SS & $d f$ & $\boldsymbol{F}$ & $\boldsymbol{p}$ \\
\hline Grit & $0.1272 \pm 0.0627$ & 0.0014 & 1 & 0.1211 & 0.7284 \\
Math confidence & $0.1609 \pm 0.0557$ & $\mathbf{0 . 1 4 5 8}$ & $\mathbf{1}$ & $\mathbf{1 2 . 8 7 0 0}$ & $\mathbf{0 . 0 0 0 4 4 9 6 * * *}$ \\
Gender (reference: male) & $-0.7522 \pm 0.8365$ & $\mathbf{0 . 0 5 5 9}$ & $\mathbf{1}$ & $\mathbf{4 . 9 3 1 5}$ & $\mathbf{0 . 0 2 7 8 5 0 3 *}$ \\
Grit * math confidence & $-0.0377 \pm 0.0168$ & $\mathbf{0 . 0 7 1 7}$ & $\mathbf{1}$ & $\mathbf{6 . 3 2 6 1}$ & $\mathbf{0 . 0 1 2 9 3 7 2 *}$ \\
Grit * gender & $0.2335 \pm 0.2451$ & $\mathbf{0 . 0 3 3 4}$ & $\mathbf{1}$ & $\mathbf{2 . 9 4 9 3}$ & $\mathbf{0 . 0 8 8 0}$ \\
Math confidence * gender & $0.1508 \pm 0.2198$ & 0.0000 & 1 & 0.0001 & 0.9907 \\
Grit*math confidence * gender & $-0.0444 \pm 0.0645$ & 0.0054 & 1 & 0.4743 & 0.4920 \\
Residuals & & 1.7219 & 152 & & \\
\hline
\end{tabular}

${ }^{\mathrm{a}} R^{2}=0.1134$.

Significance codes: $* p<0.05 ; * * p<0.01 ; * * p \leq 0.001$. Bold, $p<0.1$.

change was weakly associated with the midterm exam score ( $p$ $<0.1$ ). The midterm score and the final exam score were highly correlated with each other $(p<0.001)$. For those comparisons in which one variable is part of the calculation of another variable (i.e., pretest scores and normalized change), the correlation was not performed and is indicated by N/A in the table.

\section{DISCUSSION \\ Gender Disparities Exist in Performance but Not in Grit or Math Confidence}

In examining objective 1 to determine whether males and females differ in performance on a quantitative skills pre- and postassessment and whether males and females self-assess themselves differently in math confidence and grit, we found important differences. Notably, we found a significant difference between male and female students' performance for both the pre and post quantitative skills assessment (Figure 1). Males outperformed females by a wide margin on the preassessment. Males also significantly outperformed females on the postassessment; however, the gap in performance was reduced from $\sim 10 \%$ to $\sim 4 \%$. Corresponding to the pattern in pre- and postassessments was a significantly higher average normalized change score for females relative to males (Figure 2). Both males and females showed a significant improvement in quantitative skills over the semester, but females showed a significantly greater improvement. Despite differences between males and females in performance on quantitative assessments, there was no difference between males and females in terms of average grit and average math confidence (Figure 3). Previous studies examining grit and gender have mixed results, with either no relationship between grit and gender or females having slightly higher grit scores than males (Batres, 2011; Bazelais et al., 2016). Therefore, the lack of a difference between males and females in grit is not unexpected. The lack of an average difference between males and females in math confidence is to some extent unexpected, but encouraging, given a history of differences in math confidence between males and females (Fennema and Sherman, 1976; Nosek et al., 2002). Given the study design, we cannot fully explore why males and females self-assess similarly in math confidence. However, because the gender gap in the assessed quantitative skills is significantly decreased in such a short time frame and there is a significant correlation with math confidence and performance (pre/postassessment, midterm score, and final exam score), perhaps the lack of difference in math confidence represents a relatively accurate self-assessment of quantitative abilities. If the initial large reduction in performance for females is the result of stereotype threat (Spencer et al., 1999, 2016), females may still self-assess as being equally confident in their math abilities relative to males. If the stereotype threat for females lessens during the semester (for many potential reasons-having a female instructor, practice with quantitative skills in low-stakes conditions-as discussed in the Instructor Actions section), this could explain why we see males and females performing more similarly by the end of the semester and self-assessing their math confidence similarly.

\section{Gender, Math Confidence, and a Negative Math Confidence * Grit Interaction Predicts Student Performance}

In examining objective 2 to determine whether quantitative skills pre- and postassessment performance is predicted by math confidence, grit, and gender, we found evidence that these are important factors for student performance. In

TABLE 5. Spearman's correlation coefficients for grit, math confidence, pretest score, posttest score, normalized change, midterm score, final exam score and final grade in a second-year undergraduate biology course

\begin{tabular}{|c|c|c|c|c|c|c|c|c|}
\hline & Grit & $\begin{array}{c}\text { Math } \\
\text { confidence }\end{array}$ & Pre & Post & $\begin{array}{c}\text { Normalized } \\
\text { change }\end{array}$ & $\begin{array}{l}\text { Midterm } \\
\text { score }\end{array}$ & $\begin{array}{c}\text { Final exam } \\
\text { score }\end{array}$ & Final grade \\
\hline Grit & 1 & & & & & & & \\
\hline Math confidence & 0.0190 & 1 & & & & & & \\
\hline Post & -0.0387 & $0.2302 * *$ & $0.4109 * * *$ & 1 & & & & \\
\hline Normalized change & 0.0664 & 0.0312 & $\mathrm{~N} / \mathrm{A}$ & $\mathrm{N} / \mathrm{A}$ & 1 & & & \\
\hline Midterm score & 0.1474 & $0.1602 *$ & $0.2020 * *$ & $0.3470 * * *$ & 0.1536 & 1 & & \\
\hline Final grade & 0.1516 & 0.1379 & 0.0937 & $0.2250 * *$ & 0.1275 & N/A & N/A & 1 \\
\hline
\end{tabular}

Significance codes: Bold, $p<0.1 ; * p<0.5 ; * * p<0.01 ; * * * p \leq 0.001$. 
predicting preassessment performance, we found that, when gender, grit, and math confidence are examined together to predict students' performance on the quantitative skills preassessment, math confidence, gender, and an interaction between math confidence and grit are significant factors explaining variation in pretest score (Table 2). Together, these factors explained about $25 \%$ of the variation in students' pretest scores. While more confident students performed better than less confident students, the negative interaction between math confidence and grit is interesting, in that, as math confidence increases, the positive effect of grit on pretest scores is reduced. This indicates to us an aspect of "over confidence" in high grit-high math confident students that is associated with lower performance on the preassessment. For undergraduates to self-assess math confidence and have this self-assessment accurately correspond to performance requires a high level of metacognitive ability (Everson and Tobias, 1998). Students with weaker metacognitive skills or students who are novices with respect to quantitative skills are likely to overestimate rather than underestimate their abilities (Kruger and Dunning, 1999). This tendency for novices to overestimate their abilities may explain why the high grit-high math confident students underperform on the quantitative skills preassessment. We also see from this negative interaction that the positive impact of grit is observed more strongly for students with less math confidence. This is encouraging, in that students' performance can be improved if they are grittier, even when they have low confidence in this subject.

When the change in student performance over the semester, calculated as normalized change, was examined, gender was a weakly significant predictor of change (Table 3 ). This is consistent with the observation that females had, on average, higher normalized change scores. However, none of the other examined factors (grit or math confidence) or their interactions were significant predictors of the normalized change over the semester. Given relationships between grit and success, we had anticipated that grittier students would show greater improvements in quantitative skills during the semester; however, this was not the case. Perhaps this is due to grit being a measure of long-term persistence for goals, whereas we measured the change in quantitative skills over a relatively short period.

When factors explaining variation in posttest scores were examined, math confidence and gender were again significant predictors of performance (Table 4). Students who were more confident in math performed better on the postassessment, and males outperformed females. As in the pretest, there remained a significant negative interaction between math confidence and grit on posttest scores. The weakly positive interaction between gender and grit indicates that there was a stronger positive effect of grit on posttest scores for females relative to the males. However, we are hesitant to make too strong of a conclusion from this based on the borderline statistical significance $(p=0.08)$.

\section{Grit and Math Confidence Are Associated with Student Success in the Course Overall}

In examining objective 3 to determine patterns of association between the variables in our study, we found that grit is moderately positively associated with performance on a high-stakes assessment (midterm exam) as well as the final grade in the course (Table 5). Grit has been correlated with self-reported measures of student achievement (Bowman et al., 2015; Duckworth et al., 2007; Strayhorn, 2013); however, up to this point, there has been limited evidence of grit as a predictor of students' achievement and grades when measures are not self-reported (however, see Ivcevic and Brackett, 2014; Wolters and Hussain, 2015). It is interesting that grit correlates to academic achievement for measures that capture performance over longer periods of time and incorporate multiple course components (i.e., final grade) rather than performance on a single targeted assessment, such as, the pre-post quantitative skills assessment. The final grade included components such as multiple written lab reports, which require working toward a deadline, and performance on high-stakes cumulative exams, thereby capturing consistent effort throughout the semester on all components of the course. Because grit includes the dimension of perseverance of effort, it seems reasonable that grit would better correlate to these kinds of summative measures requiring longer-term perseverance.

Math confidence was positively associated with performance on the pre- and postassessments, as well as midterm exam score. The performance of students on the quantitative skills assessment was also positively associated with performance on the midterm and the final exam and the final grade. The relationship between the quantitative skills assessment performance and course performance could be the result of a link between quantitative skills and the ability of students to apply their quantitative skills to be successful in the course. Alternatively, students who perform well on the pre- and postassessments may be high performers on assessments in general.

Integrating these three objectives indicates that, in addition to the significant underperformance of females relative to males on the quantitative skills preassessment, math confidence and grit are also important for understanding student performance in this context. While the gender gap in performance does not completely disappear during the semester, females do show a larger gain in this short time frame, and the gender gap is almost closed. This implies to us that the gender effect captured strongly in the preassessment can be significantly reduced in a short time frame; however, we are unable to explain why the gap decreased, given the lack of an association with math confidence and grit, but it is encouraging and suggests this is not a static, deeply ingrained pattern. Despite this encouraging change during the semester, we are still troubled that in this numerically female-dominated discipline, females underperform relative to males in these skills. Our results are also unexpected, given more recent studies that have indicated in broader contexts that the gender gap in performance on math assessments is disappearing (Guiso et al., 2008; Hyde et al., 2008; Cheryan, 2012). However, from this study, it is apparent that neglecting to be conscious of gender or low math confidence in a teaching practice could have implications for student success in biology courses. In the next section, we will highlight the main outcomes from this study and provide "instructor actions" to incorporate in the classroom to address the findings here. These are not actions tested during this study, rather they are actions supported by evidence from the literature, the importance of which are highlighted by the outcomes of this study.

\section{Implications for Classroom Instruction}

Outcome-Gender. In an undergraduate biology course, females underperform relative to males on a quantitative skills assessment. 


\section{Instructor Actions}

1. Become conscious of stereotype threat. Consider how you and your course materials and examples may communicate stereotype threat in the classroom and during assessments. Stereotype threat is the underperformance of individuals belonging to a certain group based on their perceived expectation of poor performance due to membership in that group (Steele and Aronson, 1995; Spencer et al., 2016). This is important for females in math assessments, courses, and disciplines (Spencer et al., 1999; Oswald and Harvey, 2001; Good et al., 2008). To decrease the chance that stereotype threat is influencing students' performance in quantitative courses, stating that assessments are gender fair (Spencer et al., 1999) and reframing math assessments/problems as an achievable challenge (Alter et al., 2010) are successful approaches. Invoking stereotype boost, such as "University students are good at math," can counteract negative stereotype threat experienced by females around math (Rydell and Boucher, 2010). For more resources on stereotype threat, see www.reducingstereotypethreat.org.

2. Provide examples and/or provide opportunities for females to demonstrate math competency in your course (Marx and Roman, 2002; Lockwood, 2006)

3. Give nonthreatening opportunities for practice and feedback with quantitative skills before an assessment, particularly because failing to do so appears to negatively impact female performance more than male performance (for principles of formative assessment, see Nicol and Macfarlane-Dick, 2006).

Outcome-Math Confidence. Having strong quantitative skills entering a course and developing these skills during the semester is associated with higher student success in a quantitatively demanding biology course. Low confidence in math is associated with poorer quantitative skills, poorer performance on high-stakes assessments, and poorer performance in an undergraduate biology course.

\section{Instructor Actions}

1. Assess the quantitative preparedness of students entering a course with respect to important quantitative skills. Make explicit the importance of quantitative skills required for success in a course and provide resources and opportunities for practice with these quantitative skills (for ways to assess students in class, see Angelo and Cross, 1993).

2. Adopt tools and resources for developing quantitative skills in biology (Chiel et al., 2010; Speth et al., 2010; Thompson et al., 2010).

3. Consider drawing graphs and writing equations by hand during lecture and encourage your students to take handwritten notes in class (Mueller and Oppenheimer, 2014; Bui and McDaniel, 2015). This can slow the pace at which mathematical concepts are delivered and allow time for the students to process mathematical concepts.

Outcome-Grit. Grit is associated with course performance on a high-stakes assessment and overall performance in an undergraduate biology course.

\section{Instructor Actions}

1. Provide students with evidence that grittier students are more successful academically (Ivcevic and Brackett, 2014; Wolters and Hussain, 2015; the present study). Grit involves perseverance in the face of adversity, overcoming failure, persistence, and mobilization of a growth mind-set (Duckworth et al., 2007).

2. Encourage grit in your students by how you respond to a student's "failure" and how you frame your own failures. You can use language that indicates we as teachers believe in a growth mind-set and that intelligence is not fixed. Success is achievable for all of our students (Dweck, 2006).

3. Provide assessment opportunities that allow students to achieve mastery through repeated attempts rather than expecting mastery only on the first attempt.

\section{Study Limitations}

This study was conducted in a single class, with a single instructor, and at a particular institution. The patterns that exist here may not apply to other institutions or classes. Examining whether this pattern persists at other institutions with different instructors and students is an important next step. Furthermore, gender gaps can exist when students are tested with questions of higher cognitive difficulty as measured in terms of Bloom's taxonomy level (Wright et al., 2016). Our quantitative skills test questions on the pre- and postassessments may be the type of questions that lead to gender disparities, independent of the quantitative nature of the questions. Designing a study in which assessment questions are matched in terms of cognitive difficulty with and without a quantitative component may help to further isolate the disparities in performance on quantitative skills assessment. Additionally, given that students had to consent to be a part of this study, there may be a self-selection bias; however, we anticipate that the effect of this would be small, given the high participation rate (93\%). While the subscale of math confidence used has high factor structure coefficients and high reliability (as tested by Cronbach's alpha), the subscale as used may not fully capture all the aspects of math confidence. In future studies, the entire 15-item scale should be used. The adjusted $R^{2}$ values for our predictive models are relatively low (0.24 and 0.11 ), indicating that there are other factors not considered in this study that are important in predicting pre- and posttest scores of students.

\section{CONCLUSIONS}

In examining student success in an undergraduate biology course and in the acquisition of quantitative skills, we have explored several variables related to student performance. Students who are more confident in math outperformed less confident students on the quantitative skills pre- and postassessments. Students with strong quantitative skills and more grit also performed better overall in the course. Although females underperformed by males by $10 \%$ on the pretest, this gap was significantly reduced by the end of the semester. While the scope of this study is limited, these findings are important, because they provide insight into factors influencing student performance in a typical undergraduate biology course and, therefore, actions we as teachers can take to promote learning. 


\section{ACKNOWLEDGMENTS}

K.M.F. acknowledges Leslie Reid and Cindy Graham for guidance in the design and implementation of this research through their C-LAB initiative. K.M.F. is also grateful to the Taylor Institute of Teaching and Learning's SoTL writing group led by Nancy Chick at the University of Calgary for feedback (and encouragement) on drafts of this article. Thank you to Louise Hahn for providing administrative support in the implementation of this research. This study complies with the University of Calgary's Research Ethics Board (REB Study ID: 13-0689).

\section{REFERENCES}

Ahmed, W., Minnaert, A., Kuyper, H., \& van der Werf, G. (2012). Reciprocal relationships between math self-concept and math anxiety. Learning and Individual Differences, 22(3), 385-389. https://doi.org/10.1016/j lindif.2011.12.004

Aikens, M. L., \& Dolan, E. L. (2014). Teaching quantitative biology: Goals, assessments, and resources. Molecular Biology of the Cell, 25(22), 34783481. https://doi.org/10.1091/mbc.E14-06-1045

Alter, A. L., Aronson, J., Darley, J. M., Rodriguez, C., \& Ruble, D. N. (2010). Rising to the threat: Reducing stereotype threat by reframing the threat as a challenge. Journal of Experimental Social Psychology, 46(1), 166171. https://doi.org/10.1016/j.jesp.2009.09.014

Angelo, T. A., \& Cross, K. P. (1993). Classroom assessment techniques: A handbook for college teachers (The JosseyBass Higher and Adult Education Series). San Francisco: Jossey-Bass.

Ashcraft, M. H. (2002). Math anxiety: Personal, educational, and cognitive consequences. Current Directions in Psychological Science, 11(5), 181185. https://doi.org/10.1111/1467-8721.00196

Batres, I. (2011). The relationship of grit, subjective happiness and meaning in life on alternative education students' GPA and attendance. (Unpublished doctoral dissertation). University of La Verne, La Verne, CA

Bazelais, P., Lemay, D. J., \& Doleck, T. (2016). How does grit impact college students' academic achievement in science? European Journal of Science and Mathematics Education, 4(1), 33-43.

Beilock, S. L., Gunderson, E. A., Ramirez, G., \& Levine, S. C. (2010). Female teachers' math anxiety affects girls' math achievement. Proceedings of the National Academy of Sciences USA, 107(5), 1860-1863. https://doi .org/10.1073/pnas.0910967107

Betz, N. E. (1978). Prevalence, distribution, and correlates of math anxiety in college students. Journal of Counseling Psychology, 25(5), 441-448. https://doi.org/10.1037/0022-0167.25.5.441

Bialek, W., \& Botstein, D. (2004). Introductory science and mathematics education for 21st-century biologists. Science, 303(5659), 788-790.

Bowman, N. A., Hill, P. L., Denson, N., \& Bronkema, R. (2015). Keep on truckin' or stay the course? Exploring grit dimensions as differential predictors of educational achievement, satisfaction, and intentions. Social Psychological and Personality Science, 6(6), 639-645. https://doi .org/10.1177/1948550615574300

Bui, D. C., \& McDaniel, M. A. (2015). Enhancing learning during lecture note-taking using outlines and illustrative diagrams. Journal of Applied Research in Memory and Cognition, 4(2), 129-135. https://doi.org/ 10.1016/j.jarmac.2015.03.002

Casad, B. J., Hale, P., \& Wachs, F. L. (2015). Parent-child math anxiety and math-gender stereotypes predict adolescents' math education outcomes. Frontiers in Psychology, 6, 1597. https://doi.org/10.3389/fpsyg.2015.01597

Chen, J.-Q., McCray, J., Adams, M., \& Leow, C. (2013). A survey study of early childhood teachers' beliefs and confidence about teaching early math. Early Childhood Education Journal, 42(6), 367-377. https://doi .org/10.1007/s10643-013-0619-0

Cheryan, S. (2012). Understanding the paradox in math-related fields: Why do some gender gaps remain while others do not? Sex Roles, 66(3-4), 184-190. https://doi.org/10.1007/s11199-011-0060-z

Chevalier, C. D., Ashley, D. C., \& Rushin, J. W. (2010). Acquisition and retention of quantitative communication skills in an undergraduate biology curriculum: Long-term retention results. Journal of College Science Teaching, 39, 64-70.

Chiel, H. J., Mcmanus, J. M., \& Shaw, K. M. (2010). From biology to mathematical models and back: Teaching modeling to biology students, and biology to math and engineering students. CBE-Life Sciences Education, 9(3), 248-265. https://doi.org/10.1187/cbe.10-03-0022

Cohen, J. E. (2004). Mathematics is biology's next microscope, only better; biology is mathematics' next physics, only better. PLOS Biology, 2(12) https://doi.org/10.1371/journal.pbio.0020439

Colon-Berlingeri, M., \& Burrowes, P. A. (2011). Teaching biology through statistics: Application of statistical methods in genetics and zoology courses. CBE-Life Sciences Education, 10(3), 259-267. https://doi.org/ 10.1187/cbe.10-11-0137

Cvencek, D., Meltzoff, A. N., \& Greenwald, A. G. (2011). Math-gender stereotypes in elementary school children. Child Development, 82(3), 766-779. https://doi.org/10.1111/j.1467-8624.2010.01529.x

Duckworth, A. L., Kirby, T. A., Tsukayama, E., Berstein, H., \& Ericsson, K. A (2011). Deliberate practice spells success: Why grittier competitors triumph at the national spelling bee. Social Psychological and Personality Science, 2(2), 174-181. https://doi.org/10.1177/1948550610385872

Duckworth, A. L., Peterson, C., Matthews, M. D., \& Kelly, D. R. (2007). Grit: Perseverance and passion for long-term goals. Journal of Personality and Social Psychology, 92(6), 1087-1101. https://doi.org/10.1037/0022 -3514.92.6.1087

Duckworth, A. L., \& Quinn, P. D. (2009). Development and validation of the short grit scale (Grit-S). Journal of Personality Assessment, 91(2), 166174. https://doi.org/10.1080/00223890802634290

Dweck, C. S. (2006). Mindset: The new psychology of success, New York: Random House.

Dweck, C. S. (2008). Mindsets and math/science achievement. New York (17/08/2009), 1-17. Retrieved from www.opportunityequation.org

Eddy, S. L., Brownell, S. E., \& Wenderoth, M. P. (2014). Gender gaps in achievement and participation in multiple introductory biology classrooms. CBE-Life Sciences Education, 13(3), 478-492. https://doi.org/10.1187/ cbe.13-10-0204

Everson, H. T., \& Tobias, S. (1998). The ability to estimate knowledge and performance in college: A metacognitive analysis. Instructional Science, 26(1), 65-79. https://doi.org/10.1023/A:1003040130125

Fennema, E., \& Sherman, J. (1976). Fennema-Sherman Mathematics Anxiety Scales: Instruments designed to measure attitudes towards the learning of mathematics by females and males. Journal for Research in Mathematics Education, 7(5), 324-326. https://doi.org/10.2307/748467

Feser, J., Vasaly, H., \& Herrera, J. (2013). On the edge of mathematics and biology integration: Improving quantitative skills in undergraduate biology education. CBE-Life Sciences Education, 12(2), 124-128. https://doi .org/10.1187/cbe.13-03-0053

Good, C., Aronson, J., \& Harder, J. A. (2008). Problems in the pipeline: Stereotype threat and women's achievement in high-level math courses. Journal of Applied Developmental Psychology, 29(1), 17-28. https://doi .org/10.1016/j.appdev.2007.10.004

Goodwin, B., \& Miller, K. (2013). Grit + talent = student success. Educational Leadership, 71(1), 74-76

Guiso, L., Monte, F., Sapienza, P., \& Zingales, L. (2008). Diversity: Culture, gender, and math. Science, 320(5880), 1164-1165. https://doi.org/ 10.1126/science.1154094

Gunderson, E. A., Ramirez, G., Levine, S. C., \& Beilock, S. L. (2012). The role of parents and teachers in the development of gender-related math attitudes Sex Roles, 66(3), 53-166. https://doi.org/10.1007/s11199-011-9996-2

Hyde, J. S., Lindberg, S. M., Linn, M. C., Ellis, A. B., \& Williams, C. C. (2008). Gender similarities characterize math performance. Science, 321(5888), 494-495. https://doi.org/10.1126/science.1160364

Ivcevic, Z., \& Brackett, M. (2014). Predicting school success: Comparing conscientiousness, grit, and emotion regulation ability. Journal of Research in Personality, 52, 29-36. https://doi.org/10.1016/j.jrp.2014.06.005

Jansen, B. R. J., Louwerse, J., Straatemeier, M., Van der Ven, S. H. G., Klinkenberg, S., \& Van der Maas, H. L. J. (2013). The influence of experiencing success in math on math anxiety, perceived math competence, and math performance. Learning and Individual Differences, 24, 190-197. https://doi.org/10.1016/j.lindif.2012.12.014 
Kiefer, A. K., \& Sekaquaptewa, D. (2007). Implicit stereotypes and women's math performance: How implicit gender-math stereotypes influence women's susceptibility to stereotype threat. Journal of Experimental Social Psychology, 43(5), 825-832. https://doi.org/10.1016/j.jesp.2006 .08 .004

Krinzinger, H., Kaufmann, L., \& Willmes, K. (2009). Math anxiety and math ability in early primary school years. Journal of Psychoeducational Assessment, 27(3), 206-225. https://doi.org/10.1177/0734282908330583.Math

Kruger, J., \& Dunning, D. (1999). Unskilled and unaware of it: How difficulties in recognizing one's own incompetence lead to inflated self-assessments. Journal of Personality and Social Psychology, 77(6), 1121-1134. https://doi.org/10.1037/0022-3514.77.6.1121

Lefevre, J. A., Kwarchuk, S. L., Smith-Chant, B. L., Fast, L., Kamawar, D., \& Bisanz, J. (2009). Home numeracy experiences and children's math performance in the early school years. Canadian Journal of Behavioural Science, 41(2), 55-66. https://doi.org/10.1037/a0014532

Lockwood, P. (2006). "Someone like me can be successful": Do college students need same-gender role models? Psychology of Women Quarterly, 30(1), 36-46. https://doi.org/10.1111/j.1471-6402.2006.00260.x

Luckenbill-Edds, L. (2002). The educational pipeline for women in biology: No longer leaking? BioScience, 52(6), 513-521. https://doi.org/10.1641/ 0006-3568(2002)052[0513:TEPFWI]2.0.CO;2

Marx, D. M., \& Roman, J. S. (2002). Female role models: Protecting women's math test performance. Personality and Social Psychology Bulletin, 28(9), 1183-1193. https://doi.org/10.1177/01461672022812004

Marx, J. D., \& Cummings, K. (2007). Normalized change. American Journal of Physics, 75(2007), 87. https://doi.org/10.1119/1.2372468

Miller, H., \& Bichsel, J. (2004). Anxiety, working memory, gender, and math performance. Personality and Individual Differences, 37(3), 591-606. https://doi.org/10.1016/j.paid.2003.09.029

Mueller, P. A., \& Oppenheimer, D. M. (2014). The pen is mightier than the keyboard: Advantages of longhand over laptop note taking. PsychologicalScience,25(6),1159-1168. https://doi.org/10.1177/0956797614524581

Mulhern, F., \& Rae, G. (1998). Development of a shortened form of the Fennema-Sherman Mathematics Attitudes Scales. Educational and Psychological Measurement, 58(2), 295-306. https://doi.org/10.1177/ 0013164498058002012

Murphy, L., \& Thomas, L. (2008). Dangers of a fixed mindset. ACM SIGCSE Bulletin, 40(3), 271. https://doi.org/10.1145/1597849.1384344

Nicol, D. J., \& Macfarlane-Dick, D. (2006). Formative assessment and self-regulated learning: A model and seven principles of good feedback practice. Studies in Higher Education, 31(2), 199-218. https://doi .org/10.1080/03075070600572090

Nosek, B. A., Banaji, M. R., \& Greenwald, A. G. (2002). Math = male $\mathrm{me}=$ female, therefore math not $=$ me. Journal of Personality and Social Psychology, 83(1), 44-59. https://doi.org/10.1037/0022 $-3514.83 .1 .44$

Oswald, D. L., \& Harvey, R. D. (2001). Hostile environments, stereotype threat, and math performance among undergraduate women. Current Psychology, 19(4), 338-356. https://doi.org/10.1007/s12144-000-1025-5

Passolunghi, M. C., Ferreira, Rueda, T., I., \& Tomasetto, C. (2014). Math-gender stereotypes and math-related beliefs in childhood and early adoles cence. Learning and Individual Differences, 34, 70-76. https://doi .org/10.1016/j.lindif.2014.05.005
Perkins-Gough, D. (2013). The significance of grit: A conversation with Angela Lee Duckworth. Educational Leadership, 71(1), 14-20.

Ramaley, J. A. (2004). BIO2010: Transforming undergraduate education for future research biologists [review]. Review of Higher Education, 27(2), 288-289. https://doi.org/10.1353/rhe.2003.0071

Rattan, A., Good, C., \& Dweck, C. S. (2012). "It's ok-Not everyone can be good at math": Instructors with an entity theory comfort (and demotivate) students. Journal of Experimental Social Psychology, 48(3), 731 737. https://doi.org/10.1016/j.jesp.2011.12.012

Rimfeld, K., Kovas, Y., Dale, P. S., \& Plomin, R. (2016). True grit and genetics: Predicting academic achievement from personality. Journal of Personality and Social Psychology, 111(5), 780-789. https://doi.org/10.1037/ pspp0000089

Rubinsten, O., Bialik, N., \& Solar, Y. (2012). Exploring the relationship between math anxiety and gender through implicit measurement. Frontiers in Human Neuroscience, 6, 279. https://doi.org/10.3389/fnhum 2012.00279

Rydell, R. J., \& Boucher, K. L. (2010). Capitalizing on multiple social identities to prevent stereotype threat: The moderating role of self-esteem. Personality and Social Psychology Bulletin, 36(2), 239-250. https://doi org/10.1177/0146167209355062

Spencer, S., Logel, C., \& Davis, P. (2016). Stereotype threat. Annual Review of Psychology, 67, 415-437. https://doi.org/10.1146/annurev-psych-073115 $-103235$

Spencer, S. J., Steele, C. M., \& Quinn, D. M. (1999). Stereotype threat and women's math performance. Journal of Experimental Social Psychology, 35(1), 4-28. https://doi.org/10.1006/jesp.1998.1373

Speth, E. B., Momsen, J. L., Moyerbrailean, G. a, Ebert-May, D., Long, T. M., Wyse, S., \& Linton, D. (2010). 1, 2, 3, 4: Infusing quantitative literacy into introductory biology. CBE-Life Sciences Education, 9, 323-332. https:// doi.org/10.1187/cbe.10-03-0033

Steele, C. M., \& Aronson, J. (1995). Stereotype threat and the intellectual test performance of African Americans. Journal of Personality and Social Psychology, 69(5), 797-811.

Strayhorn, T. L. (2013). What role does grit play in the academic success of Black male collegians at predominantly white institutions? Journal of African American Studies, 18(1), 1-10. https://doi.org/10.1007/s12111 -012-9243-0

Su, R., \& Rounds, J. (2015). All STEM fields are not created equal: People and things interests explain gender disparities across STEM fields. Frontiers in Psychology, 6, 189. https://doi.org/10.3389/fpsyg.2015.00189

Thompson, K. V., Nelson, K. C., Marbach-Ad, G., Keller, M., \& Fagan, W. F. (2010). Online interactive teaching modules enhance quantitative proficiency of introductory biology students. CBE-Life Sciences Education, 9(3), 277-283. https://doi.org/10.1187/cbe.10-03-0028

Wolters, C. A., \& Hussain, M. (2015). Investigating grit and its relations with college students' self-regulated learning and academic achievement. Metacognition and Learning, 10(3), 293-311. https://doi.org/10.1007/ s11409-014-9128-9

Wright, C. D., Eddy, S. L., Wenderoth, M. P., Abshire, E., Blankenbiller, M., \& Brownell, S. E. (2016). Cognitive difficulty and format of exams predicts gender and socioeconomic gaps in exam performance of students in introductory biology courses. CBE-Life Sciences Education, 15(2), ar23. https://doi.org/10.1187/cbe.15-12-0246 